Mens

Revue d'histoire intellectuelle et culturelle

François Séguin. D’obscurantisme et de lumières : la

bibliothèque publique au Québec des origines au $21^{e}$ siècle, Montréal, Hurtubise, 2016, 657 p.

\title{
Gilles Gallichan
}

Volume 17, numéro 1-2, automne 2016, printemps 2017

URI : https://id.erudit.org/iderudit/1050792ar

DOI : https://doi.org/10.7202/1050792ar

Aller au sommaire du numéro

Éditeur(s)

Centre de recherche en civilisation canadienne-française

ISSN

1492-8647 (imprimé)

1927-9299 (numérique)

Découvrir la revue

Citer ce compte rendu

Gallichan, G. (2016). Compte rendu de [François Séguin. D’obscurantisme et de lumières : la bibliothèque publique au Québec des origines au $21^{e}$ siècle,

Montréal, Hurtubise, 2016, 657 p.] Mens, 17(1-2), 172-176.

https://doi.org/10.7202/1050792ar d'utilisation que vous pouvez consulter en ligne.

https://apropos.erudit.org/fr/usagers/politique-dutilisation/ 
sur le nationalisme et ses rapports avec la religion. L'étude intéressera aussi les chercheurs qui étudient la mémoire, les commémorations et les fêtes nationales.

- Marc-André Gagnon Wilfrid Laurier University

François Séguin. D'obscurantisme et de lumières : la bibliothèque publique au Québec des origines au 21 siècle, Montréal, Hurtubise, 2016, 657 p.

On attendait depuis longtemps une synthèse sur l'histoire des bibliothèques publiques au Québec qui puisse s'imposer comme ouvrage de référence. François Séguin nous l'offre dans un livre désormais incontournable, d'une grande qualité documentaire et d'une érudition qui s'appuie assurément sur plusieurs années de recherche.

On y définit le cadre du sujet, bien limité aux « établissements qui ont contribué à un degré ou l'autre au développement de la lecture publique " (p. 14). L'auteur a donc exclu les bibliothèques d'établissements scolaire, universitaire ou professionnel, de compagnies, d'associations ou d'autres organismes. Il aurait pu faire une exception pour la Bibliothèque de la Législature, devenue la Bibliothèque de l'Assemblée nationale, qui, entre 1825 et 1965 , a offert un service de consultation et de prêt public gratuit, palliant la pauvreté de ressources documentaires dans la capitale.

Malgré cette remarque mineure, l'ouvrage offre un panorama complet de l'aventure souvent épique de la lecture publique au Québec depuis les origines. Après un aperçu du livre en Nouvelle-France, l'auteur traite des premières bibliothèques associatives, dites " publiques ", qui inaugurent le genre après la Conquête. Il y eut d'abord la Bibliothèque de Québec, fondée par le gouverneur Haldimand en 1779, et la Bibliothèque de Montréal, fondée en 1796. Dans le contexte des révolutions américaine et française, les élites coloniales souhaitaient, par ces initiatives, orienter l'opinion publique en faveur 
des politiques de la métropole. Quelques autres bibliothèques de prêt, à caractère commercial, et des cabinets de lecture sont ensuite apparus dans les villes. On pouvait y lire les gazettes et y emprunter un livre en versant un dépôt.

La révolution industrielle a joué, à son tour, un rôle dans le développement de la lecture avec l'apparition des instituts d'artisans, ou Mechanic's Institutions, qui permettaient à des artisans et à des ouvriers de mieux connaître les techniques nouvelles liées à leur travail et ainsi offrir une meilleure production. L'auteur explique bien le rôle qu'ont joué ces établissements, dont certains sont devenus le noyau originel de bibliothèques publiques.

Au début des années 1840, un bref vent d'espérance a soufflé sur le Bas-Canada, lors du passage du ventriloque philanthrope Alexandre Vattemare, qui prônait la création d'instituts culturels, véritables maisons de la culture, où la bibliothèque publique aurait été un élément central. Malgré l'enthousiasme du moment, l'élan s'est brisé sur la difficulté de fédérer les établissements existants autour de ce nouveau concept.

Néanmoins, l'idée a fait son chemin et, après quelques années, on a fondé les premiers Instituts canadiens à Montréal (1844) et à Québec (1848). Le premier, animé par l'esprit libéral et le désir d'émancipation culturelle, s'est vite heurté à l'autorité de l'évêque de Montréal, $M^{\text {gr }}$ Ignace Bourget, qui souhaitait que le clergé catholique encadre et dirige ces initiatives de lectures publiques et que l'Institut se soumette au contrôle de l'Index. Il s'en est suivi un duel entre libéraux et ultramontains, lequel a marqué la vie littéraire et idéologique du Québec jusqu’à la fin du XIX ${ }^{e}$ siècle. L'Institut de Montréal a fini par succomber aux condamnations ecclésiastiques, alors que celui de Québec a survécu en se pliant à la férule du clergé.

Cependant, à la fin du XIx ${ }^{e}$ siècle l'alphabétisation progresse et le besoin en matière de lecture se fait sentir. En lieu et place de bibliothèques d'associations ouvertes au public ou de bibliothèques municipales, le clergé propose des bibliothèques paroissiales, entièrement sous contrôle ecclésiastique, selon le modèle de l'CEuvre des 
bons livres. L'auteur souligne, avec raison, le lamentable échec de ces établissements paroissiaux, sans direction générale, sans budget assuré, sans encadrement professionnel, dont l'unique fonction était le contrôle pastoral. " La bibliothèque paroissiale, lestée d'objectifs moraux et religieux, n'a jamais cessé d'être avant tout un instrument de censure ecclésiastique et de contrôle idéologique, et partant, de résistance au pluralisme» (p. 218).

Le seul effort digne de ce nom en matière de bibliothèque cléricale fut le cas des sulpiciens à Montréal qui, après le Cabinet de lecture paroissial et le Cercle Ville-Marie, fondent en 1910 la Bibliothèque Saint-Sulpice (BSS), laquelle se voulait la première bibliothèque dédiée à la recherche de l'Amérique francophone. Son premier directeur, Ægidius Fauteux, ancien journaliste, homme de lettres et humaniste, a rassemblé à Saint-Sulpice une collection générale, littéraire et historique qui lui a permis de devenir plus tard le socle de la Bibliothèque nationale du Québec et de la Grande Bibliothèque. Après sa fermeture en 1931 en raison de la crise économique, la BSS est devenue, en 1937, une propriété de l'État québécois qui l'a rouverte en 1944. L'auteur évoque cet épisode de façon vivante et la raconte comme un feuilleton.

Ce sont les Anglo-Québécois qui ont innové du côté des bibliothèques publiques gratuites avec le Fraser Institute, qui a hérité du fonds de l'Insitut canadien de Montréal, les bibliothèques de Sherbrooke, de Stanstead et de Westmount. Cette dernière a été la première bibliothèque publique municipale québécoise. L'histoire des premières bibliothèques en milieu francophone apparaît comme une véritable saga. La municipalité de Sainte-Cunégonde, près de Montréal, a eu la sienne en 1905. L'établissement d'une bibliothèque publique à Montréal relève d'un scénario de roman d'aventures que l'ouvrage raconte de manière captivante. Le combat entre l'astringent archevêque de Montréal, $M^{\text {gr }}$ Paul Bruchési, et les éléments plus progressistes de l'époque relève d'une lutte épique que l'Église a perdue à long terme avec les avancés de la modernité du $\mathrm{xx}^{\mathrm{e}}$ siècle. 
Malheureusement, cette lutte acharnée du clergé contre les " mauvaises lectures " a imposé un retard structurel au chapitre des bibliothèques publiques, dont le Québec n'est pas encore entièrement relevé. L'Église catholique souhaitait conserver la morale de ses ouailles comme on conserve des cornichons dans le vinaigre. Livres, journaux, périodiques, imprimés divers, cinémas et bibliothèques, tout tombait sous le coup de la censure, laissant une société anémique sur le plan culturel.

Certains conservateurs, dont le premier ministre Maurice Duplessis, s'accommodaient fort bien de ce concordat avec la censure cléricale, mais les choses ont commencé à bouger après sa mort en 1959. Les premières lois encourageant la création de bibliothèques municipales ont été adoptées, et la lecture publique a trouvé sa place dans l'élaboration des premières politiques culturelles du Québec. On doit le grand tournant des réformes à Denis Vaugeois, ministre des Affaires culturelles dans le gouvernement de René Lévesque. Mais les bibliothèques ont subi le contrecoup des politiques néolibérales et leurs budgets ont été réduits, particulièrement en 1985 et en 1996, sous des gouvernements libéral et péquiste.

Le Québec a progressé en matière de bibliothèques publiques depuis cinquante ans, mais n'a pas encore comblé son grand retard historique. Longtemps vue comme un danger moral, la lecture est aujourd'hui un facteur d'intégration, d'ouverture, d'éducation et d'évasion. Les nouvelles technologies n'ont pas diminué l'intérêt du public; elles ont simplement ajouté à l'offre culturelle, et la bibliothèque publique apparaît de plus en plus comme une nouvelle agora, un espace de vie, un lieu de rencontre et de détente.

Il faut souligner la qualité de l'écriture de ce livre. Tous ceux qui veulent découvrir la longue et difficile histoire des bibliothèques publiques québécoises y prendront un grand plaisir. Louvrage aurait cependant mérité de son éditeur un meilleur traitement de l'iconographie. Les illustrations, au demeurant pertinentes et bien choisies, sont souvent d'un format trop petit, et les reproductions manquent un peu de contraste. Une meilleure mise en valeur des illustrations 
aurait ajouté un intérêt à la lecture de l'ouvrage, surtout pour ceux qui connaissent moins l'histoire du livre et des bibliothèques au Québec.

Avec une remarquable bibliographie de 22 pages, incluant des sources et des études, et un index fort utile, l'auteur fait plus que rassembler la documentation sur le sujet, il y ajoute de nouvelles informations qui mettent à jour le connu et enrichissent l'historiographie des bibliothèques. Dans Le Devoir du 6 décembre 2016, François Séguin déclarait s'honorer de son titre de bibliothécaire. La contribution qu'il offre à nos connaissances sur l'histoire des bibliothèques contribue assurément à donner à ce titre toute la noblesse qui lui revient.

- Gilles Gallichan Bibliothécaire et historien

\section{Karim Larose et Frédéric Rondeau (dir.). La contre-culture au Québec, Montréal, Les Presses de l'Université de Mon- tréal, 2016, 524 p.}

Avec ce premier collectif scientifique sur la contre-culture au Québec, on concrétise l'existence d'un champ de recherche multidisciplinaire. Les quinze chapitres couvrent large; les auteurs se sont intéressés à la musique, au cinéma, au théâtre, à la poésie, à la bande dessinée, aux arts visuels et aux discours comparés avec d'autres militantismes, en l'occurrence, féministe et homosexuel. On concrétise ainsi un effort de diversification des objets, ce qui permet de mieux saisir l'ampleur et la complexité d'un mouvement dont on avait surtout retracé les racines philosophiques et historiques puis qu'on avait analysé sous l'angle politique ${ }^{1}$. Plusieurs auteurs proposent un retour

1 Theodore Roszak, Vers une contre-culture : réflexions sur la société technocratique et l'opposition de la jeunesse, traduit par Claude Elsen, Paris, Stock, 1970; Gaétan Rochon, Politique et contre-culture : essai d'analyse interprétative, LaSalle, Hurtubise HMH, 1979; Jules Duchastel, «La contre-culture, une idéologie de l'apolitisme », dans Association canadienne des sociologues et anthropologues de langue française, La transformation du pouvoir au Québec : actes du colloque de l'ACSALF, Laval, Éditions coopératives Albert Saint-Martin, 1979, p. 253-264. 